\title{
PROPOSTA DE GERENCIAMENTO DOS RESÍDUOS SÓLIDOS PRODUZIDOS NO COMANDO DE POLÍCIA INTERIOR: CPI-8
}

Lucas Prado Osco ${ }^{1}$, Leila Maria Couto Esturaro Bizarro ${ }^{2}$, Isabela Marega Rigolin ${ }^{2}$, Victor Roberto Ferreira de Melo $^{3}$

${ }^{1}$ Engenheiro Ambiental, pela UNOESTE, Aluno Especial do MMADRE - UNOESTE. ${ }^{2}$ Docente do curso de Engenharia Ambiental - UNOESTE. ${ }^{3}$ Engenheiro Ambiental, pela UNOESTE - PP. E-mail: lucas_prado_123@hotmail.com

\section{RESUMO}

O presente trabalho tem por objetivo a proposta de gerenciamento dos resíduos sólidos produzidos no Comando de Polícia Militar do Interior (CPI-8), localizado na região urbana do município de Presidente Prudente - SP, buscando adequar a corporação a um padrão socioambiental exigido. $O$ trabalho foi realizado por meio de estudos bibliográficos sobre resíduos sólidos, seu gerenciamento, bem como práticas de educação ambiental, além do levantamento de dados por meio da separação, pesagem e caracterização dos resíduos sólidos, da qual se pode obter sua quantificação. Por meio destas análises foi possível reproduzir resultados que determinam as condições atuais do volume de resíduos gerados, assim como suas respectivas classificações. Por fim, o projeto buscou elaborar uma proposta ambientalmente correta para o gerenciamento desses resíduos sólidos.

Palavras-chave: Degradação Ambiental. Impactos Ambientais. Educação Ambiental. Ecoponto.

\section{INTRODUÇÃO E OBJETIVO}

Os resíduos sólidos, uma vez que não recebam os devidos cuidados, sua separação, classificação e destinação ambientalmente correta, deverá acarretar uma série de danos às condições ambientais. De acordo com a NBR № 10.004/04, um resíduo sólido somente é considerado perigoso quando suas propriedades físicas, químicas e infectocontagiosas representam risco ao meio ambiente e risco à saúde pública quando manuseados de forma inadequada. Porém esta forma inadequada é uma prática comum em relação aos seus tratamentos. Assim, os resíduos por apresentarem grande variedade de propriedades necessitam de cuidados específicos de acordo com suas características.

Segundo a ABNT (Associação Brasileira de Normas Técnicas), por meio da Norma Brasileira (NBR) 12.980/1993, resíduo é todo material desprovido de utilidade pelo seu possuidor. O conceito, portanto, abrange todo o produto que resulta de uma atividade sendo esta de ordem usual ou cultural. Por conseguinte, os resíduos sólidos podem ser reduzidos previamente em sua produção, mesmo antes de serem formados, por meio de planos de educação ambiental, que visa o aproveitamento ou reaproveitamento do produto antes do mesmo tornar-se propriamente resíduo. 
O essencial, entretanto, está não apenas na conceituação de resíduos de uma maneira geral, mas como também em defini-los a respeito de suas propriedades e condições a que devem ser submetidos para realizar-se um aproveitamento do mesmo, sendo este reutilizado. Cosoante a ABNT 10.000/04, rejeito, ou lixo, é definido como todo resto proveniente de atividades humanas, que são considerados por seus geradores como inúteis, apresentando um estado sólido, semi-sólido ou líquido, não sendo passível de algum tipo de tratamento convencional.

Quanto à classificação dos resíduos sólidos, de acordo com Bidone (1999), adotados critérios, como sua origem, os mesmos podem ser classificando-os em: urbanos; industriais; de serviços de saúde; radioativos; agrícolas. E quanto ao grau de degradabilidade, sugere à classificação em facilmente degradáveis, moderadamente degradáveis, dificilmente degradáveis e não degradáveis. No entanto, fora por meio da NBR 10.004/04 (Resíduos Sólidos - Classificação), que se estipularam critérios de periculosidade para a classificação dos resíduos como inflamabilidade, corrosividade, reatividade, toxidade e patogenicidade.

A importância de um gerenciamento ambientalmente adequado para os resíduos sólidos é de extrema importância, não somente à unidade geradora, como também a toda a sociedade. Este é um interesse que deve partir da empresa ou instituição a que, uma vez economizando na redução do consumo e desperdícios, também serve como um exemplo e espelho para demais organizações, além de receber prioridades em busca por recursos. Deve-se, portanto elaborar um plano de gerenciamento de resíduos sólidos. Segundo o Ministério do Meio Ambiente citado pelo (FNMA) Fundação Nacional do Meio Ambiente (2001):

O plano de gerenciamento é um documento que apresenta a situação atual do sistema de limpeza urbana, com a pré-seleção das alternativas mais viáveis, com o estabelecimento de ações integradas e diretrizes sob os aspectos ambientais, econômicos, financeiros, administrativos, técnicos, sociais e legais para todas as fases de gestão dos resíduos sólidos, desde a sua geração até a destinação final.

O plano deve conter um diagnóstico da atual situação, de forma que apresenta os aspectos institucionais, legais, administrativos, financeiros, sociais, educacionais, operacionais e ambientais do sistema de limpeza pública, além de apontar os responsáveis pela coleta e destinação adequada dos diferentes tipos de resíduos. É claro que os benefícios, tanto para o meio ambiente quanto para a sociedade são imensuráveis, pois os resíduos, quando depositados de forma inadequada resultam danos diversos, ao meio ambiente e a sociedade. Por outro lado a 
destinação correta minimiza a possibilidade de impactos nocivos ao meio ambiente ou até descarta estas agressões.

De acordo com a Lei $n .^{\circ} 12.305 / 10$, deve-se realizar um esforço para levantar informações a respeito da legislação ambiental e de suas responsabilidades por meio de práticas de educação ambiental, de forma a informar o cidadão, tanto sobre seus objetivos quanto sobre os seus deveres em fazer parte de uma sociedade que busca um desenvolvimento limpo e sustentável. A elaboração de projetos no âmbito de gestão e educação ambiental, acompanhados com campanhas governamentais, além de medidas de iniciativa privada, deve contribuir para estas ações, de forma a reduzir o abismo entre a lei e a população brasileira.

Desta maneira, faz-se uso de meios à qual envolvam métodos de recuperação, reaproveitamento, ou então, a destinação correta dos resíduos gerados. O gerenciamento de resíduos sólidos garante benefícios a todas as partes envolvidas em seu processo, evitando ou ao menos reduzindo os impactos ambientais provocados, além de atribuir uma responsabilidade compartilhada da vida útil dos produtos. Esta é uma das etapas mais importantes a serem desenvolvidas por uma empresa ou instituição (pública ou privada) na busca de seu espaço entre aquelas que se propõem ao comprometimento com o equacionamento dos problemas advindos de sua atividade cotidiana.

O Comando de Polícia do Interior - 8 (CPI-8) é uma destas instituições públicas que estão na busca deste comprometimento com o meio ambiente. Localizado na área urbana do município de Presidente Prudente - SP, o CPI-8 concentra e coordena toda a ação policial realizada em 21 municípios da região. Desta forma, o presente trabalho tem por objetivo propor uma solução ambientalmente correta para o gerenciamento dos resíduos sólidos gerados no 18으 BPM/I, de forma a adequar a organização a um padrão socioambiental.

\section{METODOLOGIA}

O presente trabalho é o produto de uma pesquisa realizada por meio de estudos bibliográficos e levantamento de dados, além de uma pesquisa de campo em relação à separação, caracterização e a pesagem de resíduos sólidos, em relação à disposição e ao manejo realizado sobre os mesmos, produzido pelo Comando de Polícia do Interior - 8. O CPI-8 abriga um total de 17 edificações, dividindo-os em setores. Daqueles de maior produção de resíduos, podemos identificar os seguintes: setor administrativo; setor do canil; setor da cavalaria; setor da oficina. 
Ao decorrer do ano, o $\mathrm{CPI}-8$ possui um fluxo normal de pessoas, com certo número de policiais que, juntamente com um treinamento diário dos mesmos, produzem uma quantidade significativa de resíduos sólidos. No entanto, existem duas situações que merecem maior atenção por influenciarem em muito na quantidade de pessoal existente na instituição, sendo a presença de feriados em dias úteis e o ciclo de estágio. Assim, a cada um destes períodos atribuiu-se a classificação de período de baixo fluxo, de médio fluxo e de alto fluxo de produção de resíduos. Os resíduos sólidos gerados no $\mathrm{CPI}-8$, independentes dos seus setores, são levados ao mesmo ponto e dispostos.

Durante a separação dos resíduos produzidos, optou-se por analisar a produção de resíduos em um período de seis semanas, das quais duas semanas dentro de cada um dos períodos (produção de baixo, médio e alto fluxo). Dentro destas semanas, foram escolhidos três dias para se realizarem as análises, estes coincidentemente com os dias em que a prefeitura realiza a coleta, sendo também nas terças-feiras, quintas-feiras e sábados. Após a separação dos resíduos sólidos, foi possível atribuir e identificar, por meio da caracterização de suas propriedades físicas e químicas, cada um dos tipos de resíduos encontrados no local, podendo então, classificá-los de acordo com suas características. A forma com que os resíduos sólidos foram classificados está exemplificada a seguir: resíduos recicláveis; resíduos inservíveis (rejeitos); resíduos perigosos; resíduos orgânicos.

Por meio da pesagem e da caracterização de cada tipo de resíduos de acordo com o fluxo de geração ou produção, variando entre baixo, médio e alto fluxo, foi possível encontrar o volume gerado de cada resíduo em particular. Os resultados foram divididos de acordo com cada fluxo, assim como também, em cada um dos fluxos, se dividiu os mesmos de acordo com cada característica dos resíduos.

\section{RESULTADOS}

Os resíduos recicláveis são obtidos em todos os setores do CPI-8, que uma vez separados poderão apresentar resultados satisfatórios de reaproveitamento. Já os resíduos inservíveis são produzidos em menor escala, porém, ao entrarem em contato com os demais resíduos, dificultam em sua separação, impossibilitando os mesmos de serem reaproveitados.

Aos resíduos perigosos, são em sua maior parte, provenientes do canil (devido à produção de resíduos veterinários) e da oficina (resíduos com óleo ou graxa). Os resíduos encontrados com óleo e graxa devem ser devidamente isolados dos demais, não mantendo 
contato algum com o restante dos resíduos. Resíduos considerados como orgânicos são originados do refeitório, sendo as sobras de tudo aquilo que não foi aproveitado pela cozinha. Já as folhas de árvores são recolhidas pelos próprios policiais.

Os resíduos encontrados podem ser classificados à seguinte maneira: recicláveis (plástico; papel e papelão; caixas de leite; metal; madeira; borracha; vidro e isopor), rejeitos (orgânico inservível; pano ou tecido úmido e lixo de banheiro), perigosos (resíduos veterinários e resíduos contaminados com óleo e/ou graxa) e orgânicos (folhas de árvores e restos de alimentos). Por meio das pesagens, foi possível notar a existência de uma variação significativa dos resíduos sólidos produzidos pelo CPI-8 entre os diferentes fluxos de geração. O Gráfico 1 traz uma comparação entre os tipos de resíduos de acordo com sua classificação gerados nos três fluxos de geração (alto, médio e baixo).

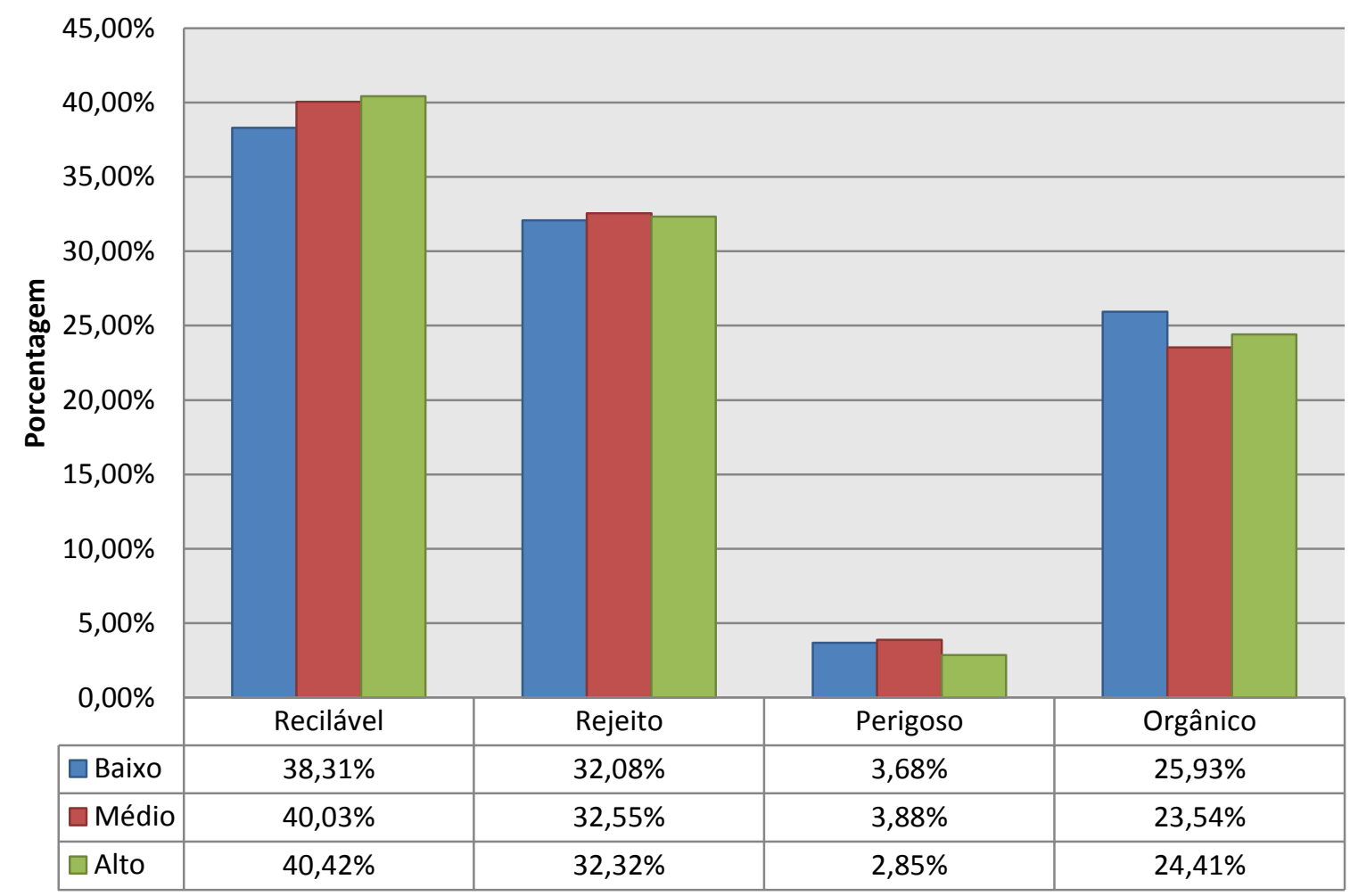

Gráfico 1. Comparação das quantidades dos resíduos de acordo com sua classificação pelo seu respectivo fluxo de geração.

Fonte: Osco, L. P.; Melo, V. R., 2012.

O CPI-8 funciona durante 24 horas por dia e em todos os dias do ano, assim sua geração de resíduos, apesar de variar ao longo dos dias devido à presença e ausência de pessoas, é ininterrupta e estima-se, por meio das pesagens realizadas, que sua geração chega a cerca de um 
total de 16.300 quilogramas de por ano em média, onde cerca de 6.450 quilogramas são recicláveis e 4.000 quilogramas são orgânicos. O Gráfico 2 indica a porcentagem de resíduos de acordo com sua classificação em relação a estimativa realizada com base nos dados coletados, fomentando um total gerado anualmente.

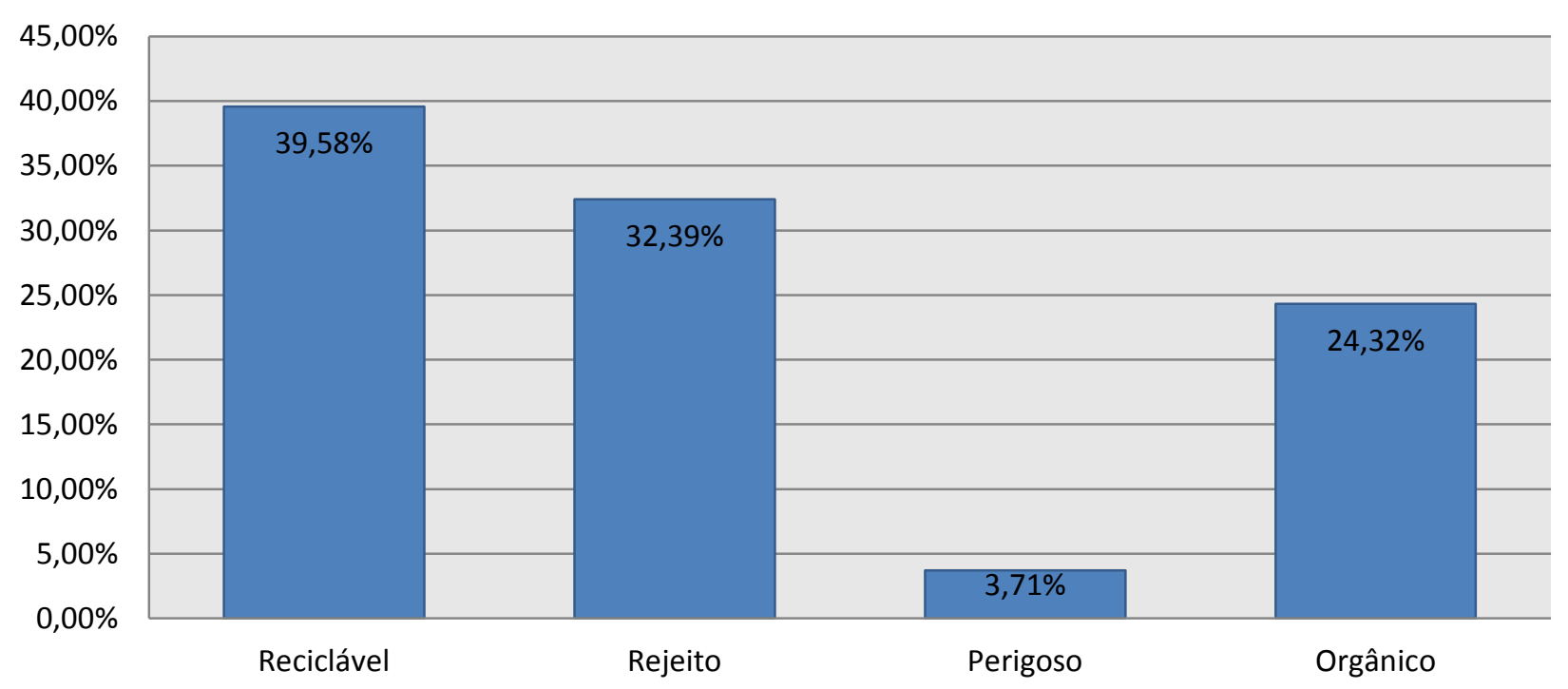

Gráfico 2. Porcentagem de resíduos gerados de acordo sua classificação e estimativa em relação ao total a ser gerado no ano.

Fonte: Osco, L. P.; Melo, V. R., 2012.

Observa-se que a maior parte dos resíduos gerados é reciclável, podendo assim ser reaproveitados e/ou reutilizados, aumentando sua vida útil, proporcionando uma economia, ao atender os requisitos, normas e padrões ambientais, diminuindo o impacto no meio ambiente, além de que com uma destinação adequada, estes resíduos podem trazer emprego e renda a outras pessoas. Da quantificação total dos resíduos nota-se que 32,93\% são rejeitos, cerca de $16,60 \mathrm{Kg}$ por dia que devem ser levados pela prefeitura, 3,71\% são resíduos perigosos, cerca de 1,77 Kg por dia que é um material que deve ser coletado por uma empresa especializada, $24,32 \%$ são resíduos orgânicos, cerca de $12,60 \mathrm{Kg}$ por dia, onde destes, $70 \%$ é reaproveitado por um dos policiais que cria porcos, os outros $30 \%$ correspondem a folhas de árvores que caem já que é feita a separação pelos próprios policiais, e a maioria dos resíduos gerados, 39,58\% são resíduos recicláveis, ou seja, 20,35kg por dia de material que está sendo desperdiçado com destinação imprópria e deve ser coletado e comercializado pela cooperativa local para que não ocorra o impacto negativo no meio ambiente. 


\section{DISCUSSÃO}

Diante da análise de estudos e pesquisas realizados em etapas anteriormente descritas, deu-se início a elaboração de gestão dos resíduos que, deve atender não só a conquista de um gerenciamento ambientalmente correto, como também, caso fosse aplicável às necessidades exigidas em cada um dos setores produtores de resíduos sólidos presentes no CPI-8. Assim se faz necessária uma proposta, de forma a garantir que os resíduos sejam separados de acordo com sua respectiva classificação (recicláveis, rejeitos, perigosos e orgânicos), como também sejam acolhidos em um local adequado para serem depositados e, adquiram uma destinação ambientalmente correta para cada um dos tipos.

Tal proposta deve dar solução a todas estas questões de gerenciamento, ao mesmo tempo em que atenda também as necessidades de cada um dos setores, cabendo a eles divisão e controle daqueles resíduos produzidos em suas atividades cotidianas. Enumera-se então, as ações necessárias para a criação de tal proposta: a redução na quantidade de lixeiras; adequação de lixeiras diferenciadas para os resíduos recicláveis, rejeitos, e orgânicos, com disposição em pontos estratégicos; a criação de um Ecoponto para a disposição e separação adequada dos resíduos; a realização de parcerias com, a cooperativa local e empresas responsáveis em destinar adequadamente os resíduos perigosos; a realização de projeto de educação ambiental para todos os envolvidos.

As lixeiras, ainda que pequenas, causam um grande desperdício, pois, mesmo que ainda não estejam cheias, são recolhidas, causando perda de dinheiro público, assim como um maior volume e excesso de sacos plásticos sendo descartado sem necessidade. Desta forma, propõe-se a existência de apenas duas lixeiras em cada sala, uma para os resíduos recicláveis e outra para os rejeitos, ou três lixeiras, com a adição da lixeira para resíduos orgânicos em locais onde se faz necessário. Quanto ao armazenamento destes resíduos para a coleta pública, o modelo que melhor se adéqua ao problema do lixo gerado é conhecido como Ecoponto, ou unidades de descarte de resíduos, ao qual se procura obter uma melhor separação e acomodação dos resíduos sólidos proporcionando também uma melhor higiene, impedindo a influencia e ação de fatores climáticos e de animais. O Ecoponto proposto para o CPI-8 deverá ter separações apenas de acordo com as características dos resíduos como abordado anteriormente, separandoos entre recicláveis, rejeito, orgânicos e perigosos.

A destinação adequada aos resíduos sólidos deve ser sempre integrada ao modelo de gestão ambiental de uma empresa ou organização. Após a separação e classificação de cada 
um dos resíduos, não adianta os mesmos receberem o mesmo tratamento e serem considerados inservíveis. Assim, ao elaborar um planejamento ambiental, deve-se voltar a atenção para formas de se realizar ou obter parcerias de empresas, sejam públicas ou privadas, que realizem a coleta destes resíduos e deem uma destinação adequada aos mesmos. Estas parcerias contribuirão para geração de renda e emprego, além de reduzirem os impactos ambientais e sociais causados pela destinação inadequada dos resíduos e do rejeito.-O CPI-8 não só irá solucionar a questão de se adequar a um padrão socialmente ambiental, como também se tornará um exemplo a ser seguido quando se fala em uma empresa ou organização ambientalmente correta.

Por fim, para que a proposta de gerenciamento de resíduos sólidos funcione adequadamente, todo o pessoal envolvido na geração de resíduos deve possuir o conhecimento adequado, do ponto de vista ambiental, dos resíduos ou rejeitos provenientes de sua atividade cotidiana, principalmente da diferenciação entre ambos. Deste modo é de extrema importância que se faça uma campanha, ou, um projeto de educação ambiental para todas as pessoas envolvidas neste processo.

\section{CONCLUSÃO}

De acordo com as análises realizadas no CPI-8 que foram: o mapeamento do local; identificação das lixeiras e pontos de geração de resíduos; separação; pesagem e classificação dos resíduos; a destinação final pode-se ter o embasamento para a criação de uma proposta ambientalmente correta com o enfoque na diminuição da geração, destinação e disposição adequada dos resíduos e uma educação ambiental adequada para todos os envolvidos. Pode-se dizer que a proposta de gerenciamento de resíduos sólidos do Comando de Polícia do Interior -8 é viável, primeiramente, por ser um órgão do governo do estado de São Paulo e que detém maior responsabilidade em se adequar ao padrão socioambiental visto que o próprio governo tenta exigir da toda sociedade, tornando a corporação um espelho, base e exemplo para demais instituições ou organizações. Por fim, estas medidas são viáveis e possíveis proporcionando um retorno ambiental e social muito grande para todas as partes envolvidas.

\section{REFERÊNCIAS}

ASSOCIAÇÃO BRASILEIRA DE NORMAS TÉCNICAS. NBR 10004. Resíduos Sólidos - Classificação. Rio de Janeiro: ABNT, 2004.'

BIDONE, F. R. A. Metodologias e Técnicas de Minimização, Reciclagem, e Reutilização de Resíduos Sólidos Urbanos. Rio de Janeiro - RJ, 1999. 
BRASIL. Lei $\mathrm{n}^{\circ}$ 12.305, de 02 de agosto de 2010. Institui a Política Nacional de Resíduos Sólidos; altera a Lei $n^{\circ} 9.605$, de 12 de fevereiro de 1998; e dá outras providências.

LOGAREZZI, A. Contribuições Conceituais Para o Gerenciamento de Resíduos Sólidos e Ações de Educação Ambiental. In: LEAL, A. C. et al. (Org.) Resíduos Sólidos no Pontal do Paranapanema. Presidente Prudente: Antônio Thomaz Júnior, p. 221-246. 2004.

MINISTÉRIO DO MEIO AMBIENTE. Fomento a Projetos de Gestão Integrada de Resíduos Sólidos Urbanos. FNMA, Edital №12, 2001. 